\title{
Die Juden um das Jahr 1000 und die antijüdischen Reaktionen auf die Jerusalemer Krise"
}

\author{
Johannes Heil
}

Nur wenig deutete um das Jahr 1000 darauf hin, dass sich nördlich der Alpen alsbald eine nennenswerte jüdische Gemeinschaft, zumal mit eigener Kultur, ausbilden würde. Man ist im rückblickenden Wissen heute leicht geneigt, die Anfänge in Mainz, Speyer und Worms in eine aufsteigende, bis Ende des 13. Jahrhunderts nur gelegentlich unterbrochene Linie fruchtbarer Entwicklung zu rücken. Aber was vom Rheinland ausgehend als Aschkenas, als jüdische Kultur von Lateineuropa, bis zur Jahrtausendwende entstand, war noch kaum gefestigt und erweist sich bei näherem Hinsehen als ausgesprochen instabil.

Vor allem fehlten die Fundamente. Denn es besteht kein Anlass, mit irgendwelchen Kontinuitäten jüdischen Lebens im Rheinland zwischen Spätantike und Mittelalter zu rechnen. Versuche zum Beweis des Gegenteils werden immer wieder einmal unternommen; die Argumente wurden zuletzt für Rouen, Köln und Regensburg vorgebracht, sie könnten für jede Stadt mit römischen Ursprüngen gelten, halten aber allesamt einer näheren Überprüfung kaum stand. Belastbare Belege für jüdische Präsenz in Trier und auch in Köln fehlen sogar bis zu den Berichten von den Kreuzzugspogromen 1096 völlig. ${ }^{1}$ Merseburg und Magdeburg

* Überarbeitete und erweiterte Vortragsfassung. Ich danke ganz herzlich meinen Freunden Andrew Gow, University of Alberta, Edmonton, und Mordechay Lewy, Botschafter des Staates Israel beim Heiligen Stuhl, für kritische Kommentare und Anregungen.

1 A. Grossman, Die ersten Gelehrten in Aschkenaz - Lebensläufe, Aufstieg zur Gemeindeführung, Werke - vom Beginn der Niederlassung bis zu den Pogromen 1096 [hebr.], Jerusalem 1988, 1-26; M. Toch, Die Juden im mittelalterlichen Reich, München 1998 (2. Aufl., 2003), 5f., 80f.; R. Ben-Shalom, Medieval Jewry in Christendom, in: M. Goodman et al. (Hg.), The Oxford Handbook of Jewish Studies, Oxford 2002, 155f.; vgl. dagegen N. Golb, The Jews in Medieval Normandy. A Social and Intellectual History, Cambridge, Mass. 1998, S. XVI, 109f.; D. Schmid, Das Regensburger Judenviertel: Topographie und Geschichte im Licht der jüngsten Ausgrabungen, in: F. Mayrhofer et al. (Hg.), Juden in der Stadt, Linz 1999, hier 168-173; S. Codreanu-Windauer, Regensburg - Archäologie des mittelalterlichen Judenviertels, in: C. Cluse (Hg.), Europas Juden im Mittelalter, Trier 2004, hier 465; M. Gechter - S. Schütte, Ursprung und Voraussetzungen des mittelalterlichen Rathauses und seiner Umgebung, in: W. Geis et al. (Hg.), Köln: Das gotische Rathaus und seine historische Umgebung, Köln 2000, hier 113f.; S. Schütte, Die Juden in Köln von der Antike bis zum Hochmittelalter. Beiträge zur Diskussion zum frühen Judentum nördlich der Alpen, in: F. Backhaus et al. (Hg.), Synagogen, Mikwen, Siedlungen. 
bieten für das zweite Viertel des 10. Jahrhunderts Belege für die Präsenz von Juden, ohne dass sich daraus Angaben über Größe und Gestalt von Niederlassungen oder gar Gemeinden gewinnen ließen. ${ }^{2}$ Einen dünnen Hinweis auf Juden in Regensburg gibt die königliche Bestätigung für den Verkauf eines vor Regensburg gelegenen Gutes im Jahr 981; Käufer war das Kloster St. Emmeram, der Eigner ein Jude mit Namen Samuel. Interessanterweise bezieht sich diese Quelle auf eine agrarisch-grundherrschaftliche Verpflichtung eines Juden; das hier zu gewinnende Bild steht in Kontrast zu den landläufigen Vorstellungen vom urban verorteten Judentum mit seinem Dienstleistungscharakter für Handel und Geldwirtschaft. ${ }^{3}$

Dichter sind die Belege für Mainz seit dem 10. und im 11. Jahrhundert. Hebräische wie auch lateinische Quellen ergänzen sich hier, doch sie zeugen zugleich von einem anhaltend wechselvollen Verlauf der frühen Geschichte der Juden. Gleich die erste Nennung von Mainzer Juden in christlichen Quellen lässt wenig Gutes erwarten. Dabei bezeichnet die Zeit um die Jahre 932-937 womöglich den Anfang jüdischer Niederlassung in Mainz, nämlich den Moment, wo der bischöfliche Stadtherr sich vor die Frage gestellt sah, ob die Niederlassung von Nichtchristen inmitten der christlichen Gemeinde statthaft sei. Ebf. Friedrich beauftragte 937 einen Priester namens Gerhard mit der Sammlung einschlägiger kirchlicher Kanones und zog die Möglichkeit, die Juden zur Taufe zu zwingen oder sie zu vertreiben, offenbar ernsthaft in Betracht. ${ }^{4}$ Dieser Mainzer Ange-

Jüdisches Alltagsleben im Lichte neuer archäologischer Funde, Frankfurt, 2004, 73-116; ferner M. Schmandt, Köln: Jüdisches Zentrum am Niederrhein, in: Cluse, a.a.O., 443f.; C. Cluse, Juden am Niederrhein während des Mittelalters - eine Bilanz, in: M. Grübel et al. (Hg.), Jüdisches Leben im Rheinland. Vom Mittelalter bis zur Gegenwart, hier 4-6; W. Rogasch, Ein jüdisches Museum für Köln. Grundzüge einer Konzeption, in: Tribüne 185 (2008), 154-162.

2 Vgl. J. Heil, „Goldenes Zeitalter“? - Juden und Judentum in der Karolingerzeit, in: R. Kampling (Hg.), „Wie schön sind Deine Zelte, Jakob, deine Wohnungen, Israel!“; Beiträge zur Geschichte europäisch-jüdischer Kultur, Frankfurt am Main etc. 2009 (Apeliotes. Studien zur Kulturgeschichte und Theologie 5), 99-114, bes. 102ff.; Ders., Zwischen Rhein und Elbe. Juden und Judentum im 13. Jahrhundert, in: M. Puhle (Hg.), Aufbruch in die Gotik. Der Magdeburger Dom und die späte Stauferzeit, Bd. 1: Essays, Mainz 2009, 422-431, bes. 427f.

3 MGH DD OII, Nr. 247, 278f. (a. 981); vgl. A. Dirmeier, Die Schierstatt von Regensburg: Frühe jüdische Siedlungsspuren, in: Staat und Verwaltung in Bayern. Festschrift Wilhelm Volkert, München 2003, 37-42; mit weiteren Belegen B. Blumenkranz, Juifs et chrétiens dans le monde occidental, 430-1096, Paris 1960, 22-30.

4 F. Lotter, Der Brief des Priesters Gerhard an den Ebf. Friedrich von Mainz. Ein kanonistisches Gutachten, Sigmaringen 1975 (Vorträge und Forschungen, Sbd. 17); vgl. K. Stow, The Church and the Jews. St Paul to Pious IX, in: Ders., Popes, Church, and Jews in the Middle Ages - Confrontation and Response, Aldershot 2007, No. I, S. 15. 
legenheit vorangegangen war ein Brief des Dogen Petrus Candidus, im Verbund mit dem Patriarchen von Grado und den Bischöfen Venetiens, der König Heinrich I. und Hildebert von Mainz zur Synode von Erfurt im Jahr 932 erreichte und der - geradezu als Vorgriff auf die Ereignisse um das Jahr 1009 - von jüdischen Übergriffen auf die Grabeskirche in Jerusalem berichtete, zu denen die Jerusalemer Juden die Muslime als Verbündete gewonnen haben sollen. Dabei ging es ferner um einen „Juden, der aus Jerusalem in die Länder König Heinrichs in der Figur des Antichristen gekommen sei, den Namen Christi geschmäht und große Bosheiten über das heilige Grab berichtete habe, etwa so, dass er, wenn er vermochte (potuisset) das Reich der Christenheit stürze und die Synagoge der Juden errichte." Im Hintergrund stand die Nachricht von einem Befehl zur Zwangstaufe der Juden im byzantinischen Reich unter Romanos I. (920-944), die der Brief als Konsequenz einer Christuserscheinung in der Jerusalemer Grabeskirche, gefolgt von der teils freiwilligen, teils erzwungen Taufe der Juden dort und an anderen Orten, berichtete. ${ }^{5}$ Ein näherer Anlass für den Ausbruch des so deutlich feindseligen Impulses lässt sich kaum bestimmen; gewiss aber greift eine Deutung, die hinter alledem nur die religiöse Bemäntelung wirtschaftlicher Konkurrenzverhältnisse erkennen will, wohl zu kurz. ${ }^{6}$

Weitere Einzelheiten über die Ereignisse sowie die Migrations- und Kommunikationswege jener Jahre lassen sich nicht gewinnen; die verfügbaren Quellen laden zu weitreichenden Deutungen ein, bieten aber kaum mehr als Schlaglichter. In der Summe hinterlassen sie das Bild einer ausgesprochen unruhigen Szenerie, in der der Platz der Juden in den christlichen Gesellschaften im Osten wie im Westen offensichtlich umstritten und anhaltend gefährdet war. In der christlichen Theologie der Zeit waren die Juden als Figur omnipräsent, aber ihre soziale Prä-

5 Der Brief des Dogen an König Heinrich: MGH Constitutiones, Bd. 1, hg. L. Weiland, Hannover 1903, 6f.; s. a. E.-D. Hehl et al. (Hg.), Die Konzilien Deutschlands und Reichsitaliens 916-1001, Teil 1: 916-960, Hannover 1987 (MGH Conc. VI,1), 113f., ferner 99f.; vgl. G. Mentgen, Die Judenvertreibungen im mittelalterlichen Reich. Ein Forschungsbericht, in: Aschkenas 16 (2006), 367ff. und 370-373; ferner B. Blumenkranz, Les Auteurs chrétiens-latins du moyen-âge sur les juifs et le judaïsme, Paris 1963, 218f. (Ndr. Löwen 2007); H. Wolter, Die Synoden im Reichsgebiet und in Reichsitalien von 916-1056, Paderborn 1988, 32; Z. Baras, A Jewish-Christian Religious Disputation in Jerusalem in 932 [hebr.], in: Cathedra 63 (1992), 31-51; R. Landes, The Massacres of 1010. On the Origins of Popular anti-Jewish Violence in Western Europe, in: J. Cohen (Hg.), From Witness to Witchcraft. Jews and Judaism in Medieval Christian Thought, Wiesbaden 1996, hier 94.

6 M. McCormick, Verkehrswege, Handel und Sklaven zwischen Europa und dem Nahen Osten um 900: Von der Geschichtsschreibung zur Archäologie?, in: J. Henning (Hg.), Europa im 10. Jahrhundert. Archäologie einer Aufbruchszeit. Internationale Tagung in Vorbereitung der Ausstellung »Otto der Große, Magdeburg und Europa«, Mainz 2002, 171-180, hier 177. 
senz war darin nicht gefasst. ${ }^{7}$ Insofern wäre es kaum stimmig, eine einfache Linie von den Schutzbriefen der karolingischen Herrscher, wie sie sich in Ausfertigung für Juden und andere Schutzbedürftige in der Formelsammlung der Kanzlei Ludwigs des Frommen aus der Zeit um 825 erhalten haben, zu den kollektiven Judenprivilegien zu ziehen, die seit dem Ende des 11. Jahrhunderts für die Gemeinden am Rhein belegt sind. ${ }^{8}$ Die Verbindung, die sich vom 9. zum 11. Jahrhundert zeichnen lässt, ist gerade einmal motivischer Art. In inhaltlicher Hinsicht ist die Entwicklung kaum gradlinig verlaufen und erscheint durch den Gang der Ereignisse, die nachfolgend beschrieben werden, markant gebrochen. ${ }^{9}$ Erst die Etablierung und das allmähliche Wachsen der jüdischen Niederlassungen an Rhein, Donau und Elbe allein korrigiert dann das Bild: dass die Umstände und Aussichten im Herrschaftsgebiet von Sachsen und Saliern in der Summe immerhin so gut gewesen sein müssen, um Juden aus dem Süden - überwiegend wohl aus dem unruhigen Süden Italiens sowie aus dem Süden Frankreichs - zur Niederlassung nördlich der Alpen zu bewegen. ${ }^{10}$

Denn es waren dies eben jene Jahrzehnte, für die sich die ersten Spuren von Gelehrten am Rhein ausmachen lassen. Da war ein gewisser Rav Leontin, dessen familiäre Wurzeln nach Zentralfrankreich verweisen. Ferner ist Gerschom ben Jehuda zu nennen, der erste große Gelehrte des Rheinlandes, genannt „Erleuchter der Diaspora", der wohl aus Metz gekommen war und der Überlieferung nach 1028 in Mainz verstarb. Kurz nach dem Jahr 1000 tritt dann auch erstmals ein Spross der süditalischen Familie Kalonymos auf den Plan, den die Quellen Meshullam „isch Romi“ nennen, also den Römer, während spätere Legenden den Ursprung der Familie nach Lucca verlegen und ihren Wechsel an den Rhein

7 J. Heil, Kompilation oder Konstruktion? Die Juden in den Pauluskommentaren des 9. Jahrhunderts, Hannover 1998, 372-390; J. Cohen, Living Letters of the Law. Jews and Judaism in Medieval Christianity, Berkeley 1999, 67-71.

8 A. Patschovsky, Das Rechtsverhältnis der Juden zum deutschen König (9.-14. Jahrhundert), in: ZRG germ. Abt. 110 (1993), 331-371; K.-U. Jäschke, Judenschutz - eine mittelalterliche Königstugend?, in: Reinhard Schneider (Hg.), Juden in Deutschland. Lebenswelten und Einzelschicksale. Ringvorlesung der Philosophischen Fakultät der Universität des Saarlandes im Wintersemester 1988/89 (= Annales Universitatis Saraviensis. Philosophische Fakultät; 1), St. Ingbert 1994, 35-149; D. Willoweit, Die rechtliche Stellung der Juden im Mittelalter, in: E. V. Kotowski et al. (Hg.), Handbuch zur Geschichte der Juden in Europa. Bd. 2, Darmstadt 2001, 299-308; Toch, Juden (s. Anm. 1), 46f. 103f.; I. G. Marcus, A Jewish-Christian Symbiosis. The Culture of Early Ashkenaz, in: D. Biale (Hg.), Cultures of the Jews. A New History, New York 2002, $455 f$.

9 Vgl. Mentgen, Judenvertreibungen (s. Anm. 5) 370f.

10 Vgl. J. Heil, „Deep Enmity“ and/or „Close Ties“? Jews and Christians before 1096, Sources, Hermeneutics, and Writing History in 1996, in: Jewish Studies Quarterly 9 (2002), 259-306. 
einem dankbar bedachten „König Karl“ zuschrieben. ${ }^{11}$ Der Süden Italiens hat überhaupt als frühmittelalterlicher Transmitterraum zwischen den alten jüdischen Zentren des Osten und den entstehenden Zentren des westeuropäischen, aschkenasischen Judentums zu gelten. Die Zonen in der westlichen Peripherie des byzantinischen Reiches boten angesichts der Repressionspolitik Kaiser Julians und seiner Nachfolger einen einigermaßen sicheren Rückzugsraum, der in den Zeiten der Auseinandersetzungen zwischen Byzantinern, Langobarden und Muslimen gewisse Entfaltungsmöglichkeiten bot, infolge der politisch-militärischen Instabilität aber auch die Ausschau nach Alternativen nahelegte. Die Aussicht auf sicherere Niederlassungsbedingungen im unbekannten Norden, im Bereich des aufstrebenden fränkischen Reiches und seiner Nachfolger, stand am Anfang der Migration von Juden aus dem Süden an den Rhein und darüber hinaus. ${ }^{12}$

Bedeutend und mit einer spätantik-frühmittelalterlichen Kontinuität versehen war auch die romano-jüdische Präsenz im Süden Galliens, mit einer - wie die zahlreichen Landtransaktionen bis ins 11. Jahrhundert belegen - überwiegend landsässigen jüdischen Bevölkerung in den Regionen südlich der Loire, mit Zentren in Orléans, Marseille und Narbonne, womöglich auch in Lyon und sonst entlang der Rhone. ${ }^{13}$ Abwehrende Reaktionen in der antijüdischen Tradition des

11 Toch, Juden (s. Anm. 1), 5, 26f., passim; ferner H.-G. von Mutius, Rechtsentscheide rheinischer Rabbinen vor dem Ersten Kreuzzug - Quellen über die sozialen und wirtschaftlichen Beziehungen zwischen Juden und Christen, Bd. 1, Frankfurt am Main etc. 1984 (Judentum und Umwelt 13), 21; E. Hollender, „Und den Rabbenu Moses brachte der König Karl mit sich“ - Zum Bild Karls des Grossen in der hebräischen Literatur des Mittelalters, in: B. Bastert (Hg.), Karl der Grosse in den europäischen Literaturen des Mittelalters. Konstruktion eines Mythos, Tübingen 2004, 183-200.

12 Vgl. E. Bammel, Gregor der Grosse und die Juden, in: Gregorio Magno e il suo tempo (= XIX Incontro di studiosi dell'antichità cristiana), Bd. 2, Rom 1991, 283-291; D. Noy, The Jews in Italy in the First to Sixth Centuries C.E., in: B. D. Cooperman et al. (Hg.), The Jews of Italy. Memory and Identity, Bethesda 2000 (Studies and Texts in Jewish History and Culture 7), 47-64; C. Colafemmina, Hebrew Inscriptions of the Early Medieval Period in Southern Italy, ebd., 64-81; E. Savino, Ebrei a Napoli nel VI secolo d.C., in: G. Lacerenza (Hg.), Hebraica hereditas. Studi in onore di Cesare Colafemmina, Neapel 2005, 299-313; M. Idel, From Italy to Ashkenaz and Back On the Circulation of Jewish Mystical Traditions, in: Kabbalab 14 (2006), 47-94; S. Dönitz, Von Italien nach Ashkenaz: Sefer Yosippon und die historiographische Tradition des Mittelalters, in: A. Kuyt et al. (Hg.), Orient als Grenzbereich: Rabbinisches und Außerrabbinisches Judentum, Wiesbaden 2008, 169-182.

13 Blumenkranz, Juifs (s. Anm. 3) 12ff.; kaum weiterführend und mit Auslassung maßgeblicher Literatur: R. Chazan, The Jews of Medieval Western Christendom, 1000 1500, Cambridge 2006, 87ff.; ebenso D. Malkiel, Reconstructing Ashkenaz. The Human Face of Franco-German Jewry, 1000-1250, Stanford 2009. 
westgotischen Spanien gegen die Präsenz von Juden sind aus Lyon für die Jahre 821-828 sowie wieder 845/46 aus den Federn der Lyoner Erzbischöfe Agobard und Amolo erhalten. Dabei haben die Kirchenleute die Auseinandersetzung mit dem Hof Ludwigs des Frommen allem Anschein nach nicht wegen der Juden, sondern zur Erreichung ganz anderer Ziele als bewusste Skandalisierungsstrategie mit dem Verweis auf die Juden geführt. Person und Politik des missliebigen Kaisers sollten mit dem Hinweis auf die angebliche besondere Wertschätzung der Nichtchristen bei Hofe desavouiert werden. ${ }^{14}$ Bemerkenswert ist, dass auf der Suche nach Bundesgenossen im Kampf gegen den Hof es Agobard im Verlauf der Auseinandersetzung aber nicht einmal gelang, Erzbischof Nibridius, das Haupt der Metropole Narbonne mit der damals wohl bedeutendsten Judengemeinde des westlichen Mittelmeerraums, zu gewinnen. ${ }^{15}$

Von der anhaltenden Instabilität jüdischer Existenz nördlich der Alpen zeugt dann wieder eine Notiz in den Annales Quedlinburgenses zu 1012, wonach „expulsio judeorum facta est a rege in moguntia, sed et quorundam haereticorum refutata est insania", demnach also durch König Heinrich II. ${ }^{16}$ Genaueres zu diesem nur randständig überlieferten Vorkommnis - ob es sich um einen kurzzeitigen lokalen Akt oder um eine weiterreichende Zwangsaktion handelte, auch welches Ausmaß sie hatte und ob die Juden und die Häretiker unmittelbar miteinander zu tun gehabt haben sollen - lässt sich aus der kurzen Notiz nicht ermitteln und ist auch sonst nirgendwo belegt. Erwähnt sei aber, dass in der Forschung von dieser Notiz Verbindungslinien zu Zerrüttungen in der Familie des Mainzer Gelehrten Gerschom ben Jehuda ausgemacht werden. Gerschoms Sohn sei damals zur Taufe gezwungen worden, und manche Wendung in einer liturgischen Dichtung des Vaters sei dann als Reaktion auf diesen Verlust zu lesen. ${ }^{17}$ Die damit vorgenommene Verbindung erscheint möglich und auch plausibel. Belegen freilich lässt sie sich ob der geringen Verlässlichkeit beider Quellen kaum. Damit ist aber noch nicht alles angesprochen, was die kurze Notiz der

14 Agobardi Lugdunensis opera omnia, ed. L. van Acker, Turnhout 1981 (CCCM 52); Amolo, in: PL 116, cols. 141-184; vgl. E. Boshof, Erzbischof Agobard von Lyon. Leben und Werk, Köln 1969; J. Heil, Agobard, Amulo, das Kirchengut und die Juden von Lyon, in: Francia. Forschungen zur westeuropäischen Geschichte 25 (1998), 39-76; ferner R. Savigni, L'immagine dell'ebreo e dell'ebraismo in Agobardo di Lione e nella cultura carolingia, in: Annali di Storia dell'Esegesi 17 (2000) 417-461.

15 Agobard, De cavendo convictu et societate iudaica, in: Agobardi opera, 229-234; vgl. Heil, Agobard (s. Anm. 14), $57 \mathrm{f}$.

16 MGH SS, Bd. 3, 81

17 Landes, Massacres (s. Anm. 5), 88; vgl. F. Lotter, Die Vertreibung der Juden aus Mainz um 1012 und der antijüdische Traktat des Hofgeistlichen Heinrich, in: F. Burgard et al. (Hg.), Judenvertreibungen in Mittelalter und früher Neuzeit, Hannover 1999, 37-74; Malkiel, Ashkenaz (s. Anm. 13), 68-70. 
Quedlinburger Annalen biete. Denn mit der Verbindung von Juden und Häretikern klingt hier, wiederum ohne Möglichkeit der Ermittlung von Einzelheiten, ein Motiv an, das auch in den christlichen Darstellungen von Ereignissen in Orléans und Limoges im Zusammenhang der Zerstörung der Grabeskirche in Jerusalem 1009 aufscheint. Es besteht zunächst also kein Anlass, im Grundsatz an der Richtigkeit der Angaben der Quedlinburger Annalen zu Mainz 1012 zu zweifeln. Aber ebenso muss die randständige Überlieferung des Geschehens in einer einzelnen Quelle beachtet werden: das Mainzer Ereignis hatte offensichtlich keine langfristigen Nachwirkungen, zumindest nicht am Rhein, denn die Gemeinde in Mainz, die Mutter von Worms und Speyer, prosperierte gerade in den Jahrzehnten nach 1000 merklich. ${ }^{18}$

Jüdische Existenz inmitten der christlichen Gesellschaft blieb in den Jahrzehnten um die Jahrtausendwende trotz anhaltenden Wachsens der Gemeinden und gemeindlich-intellektueller Strukturen also prekär und gefährdet. Das trifft nicht nur für den Herrschaftsbereich des ostfränkischen, ottonischen und salischen Königtums zu, sondern ebenso für die Juden im westfränkisch-kapetingischen Reich. Vielleicht erscheint die Beobachtung banal: aber herrscherliche Provisionen für die Juden hier wie dort fehlen, die nur randständigen Bestimmungen für Magdeburg und Merseburg einmal ausgenommen, das ganze 10. und 11. Jahrhundert hindurch. In der rechtsgeschichtlichen Überlieferung haben wir hier eine Leerstelle vor uns, die zwischen den karolingischen Judenschutzbriefen (um 825) und den ersten gemeindlichen Privilegien für die Juden am Rhein (1084/90) den beträchtlichen Zeitraum von etwa zweihundertsechzig Jahren belässt.

Erst zu Beginn des letzten Jahrzehnts des 11. Jahrhunderts unternahm Heinrich IV. - und das im Zeichen der Krisenhaftigkeit seiner eigenen Regentschaft Anstrengungen zur systematischen herrschaftsrechtlichen Erfassung und Sicherung der Position der Juden in seinem Bereich. Vorangegangen war 1084 der Speyerer Bischof, der aus Mainz in seine Stadt gekommenen Juden ein vorteilhaftes Privileg ausstellte. ${ }^{19}$ Die Pogrome des Kreuzzugsjahres 1096 haben diese

18 Cluse, Niederrhein (s. Anm. 1); G. Mentgen, Die Juden des Mittelrhein-MoselGebietes im Hochmittelalter unter besonderer Berücksichtigung der Kreuzzugsverfolgungen, in: Der Erste Kreuzzug 1096 und seine Folgen. Die Verfolgung von Juden im Rheinland, hg. Evangelische Kirche im Rheinland, Düsseldorf 1996 (Schriften Archiv EKRheinland 9), 37-75.

19 A. Hilgard, Urkunden zur Geschichte der Stadt Speyer, Straßburg 1885, Nr. 11, 11f.; vgl. ferner die kaiserlichen Privilegien für Worms und Speyer, in: MGH DD H IV, Nr. 411, 412, 543-549; Nr. 509, 679f.; vgl. Toch, Juden (s. Anm. 1) 45f. 103f.; ferner M. Suchan, Königsherrschaft im Streit. Konfliktaustragung in der Regierungszeit Heinrichs IV. zwischen Gewalt, Gespräch und Schriftlichkeit, Stuttgart 1997; B. Schneidmüller - S. Weinfurter (Hg.), Salisches Kaisertum und neues Europa. Die Zeit Heinrichs IV. und Heinrichs V., Darmstadt 2007; J. Fried, Der Pakt 
Bestimmungen nicht verhindern können; doch immerhin dürften die darin getroffenen Provisionen zum Schutz der Juden ihren Anteil daran gehabt haben, dass an einigen Orten wie Speyer schlimmeres verhindert werden konnte. ${ }^{20}$

Die Bilanz des 11. Jahrhunderts fällt auf das Ganze betrachtet eher negativ aus. Der judenfeindliche Nachklang auf die Zerstörung der Jerusalemer Grabeskirche im Jahr 1009 war dann kein Ausnahmefall, sondern fügt sich, ganz gleich ob die Ereignisse im Westen tatsächlich ihre Ursache im Wissen um die Geschehnisse in Jerusalem hatten, in das Gesamtbild der Zeit, und so bedurfte es wohl nicht notwendig besonderer endzeitlicher Impulse, um in jenen Jahren Gegnerschaft gegen die Juden zu mobilisieren. ${ }^{21}$ Denn es ist wenig wahrscheinlich, dass der durch christliche Autoren wie Origenes vorbereitete und durch Augustinus zu quasi kanonischem Rang erhobene eschatologische Vorbehalt, der den Juden wohl blinden Eifer unterstellte, ihnen dabei aber eine unfreiwillig dienende Zeugenschaft für die christliche Wahrheit einräumte, allein ausgereicht hätte, um den Juden einen einigermaßen komfortablen Platz am unteren Rand der sich formierenden christlichen Gesellschaften zu belassen. Solcherlei subtile Rationalisierungen jüdischer Präsenz waren auf die spätantike Situation im Mittelmeerraum hin formuliert gewesen. Dabei war es, stets unter heilsgeschichtlich-christlichen Vorzeichen, darum gegangen, die so nie ausgesprochene, aber offen im Raum stehende Frage zu klären, warum selbst nach dem umfassenden Triumph der Christenheit dann Judentum noch immer existierte. Und es war in den Tagen des Augustinus gegenüber jenen innerchristlichen Dissidenten, das Alte Testament insgesamt in Frage stellten, die Bedeutung der biblisch-alttestamentlichen Tradition zu verteidigen, nämlich vermittels des Beweises, dass das Neue Testament typologisch im Alten vorausgeschrieben gewesen sei und an alledem auch die Juden einen bleibenden Anteil hatten, selbst nach dem Übergang der Gottesvolkschaft an das „wahre Israel“ in der Kirche. Überhaupt sollte nichts in den Worten, Bildern und Figuren des Alten ohne Bedeutung auf das Neue hin gewesen und einzig zur Erfüllung im Neuen gesetzt gewesen sein.

Die doppelte Bindung der spätantiken christlichen Apologeten pro Iudaeis deckte sich aber nicht mit dem Blick mittelalterlicher Autoren. Ihnen galt, je wei-

von Canossa. Schritte zur Wirklichkeit durch Erinnerungsanalyse, in: W. Hartmann et al. (Hg.), Die Faszination der Papstgeschichte. Neue Zugänge zum frühen und hohen Mittelalter, Köln etc. 2008 (Regesta Imperii Beih., Bd. 28), 133-197.

20 E. Haverkamp (Hg.), Hebräische Berichte über die Judenverfolgungen während des Ersten Kreuzzugs, München 2005 (MGH Hebräische Texte aus dem mittelalterlichen Deutschland 1), 262-268; vgl. A. Haverkamp (Hg.), Juden und Christen zur Zeit der Kreuzzüge, Sigmaringen 1996 (Vorträge und Forschungen 47).

21 Die Gewalt gegen Juden im 11. Jahrhundert war daher weder „vorbildlos“, noch ist es zwingend, sie alleine aus gesteigerten endzeitlichen Impulsen zu erklären; vgl. Landes, Massacres (s. Anm. 5), 101. 
ter man nordwärts voranschritt, Judentum mangels eigener Anschauung nicht als soziale Realität, die in ihrer Weltdeutung stimmig aufgehoben sein musste, sondern höchstens als theologische Figur mit gänzlich geschichtlicher Realität. Der „hermeneutische Jude“ der karolingischen Theologie, jener Zeit also, als viel über die Juden geschrieben worden war, ohne sich mit ihrer Präsenz ernstlich befassen zu müssen, kam dann seit dem 10./11. Jahrhundert neuerlich auf den Prüfstand, nämlich in Kontrast zur sozialen Wirklichkeit, in der Juden plötzlich aktiv auftraten. Einige besonders traditionstreue Autoren wie Hrabanus Maurus hatten zuvor den kirchenväterlichen eschatologischen Vorbehalt zu Gunsten der Juden unverändert fortgeschrieben. Andere, gerade die innovativen wie Haimo von Auxerre und Florus von Lyon, hatten gegen diese Vorgaben angeschrieben und die Wiedererwählungsaussicht der Juden an zentraler Stelle, in der Auslegung von Röm. 11, ausdrücklich bestritten. Dabei mag man anführen, dass sie in Hinsicht der Juden durch ihre Haltungen in anderweitigen theologischen Debatten bestimmt waren. In der heftigen Auseinandersetzung der Mitte des 9. Jahrhunderts um Willensfreiheit und Prädestination schien das weiterhin rein geschichtlich betrachtete Beispiel der Juden besonders zum Beleg der Unbedingtheit göttlicher Vorausbestimmung geeignet. ${ }^{22}$ Es war das theologische Milieu aber nicht vom sozialen $\mathrm{zu}$ trennen. Nicht von ungefähr nahmen von Lyon, einem der führenden geistigen Zentren, auch die judenfeindlichen politisch-sozialen Kampagnen der Zeit ihren Ausgang. ${ }^{23}$

Am Beispiel der mittelalterlichen Versionen des ordo prophetarum und der eschatologischen Zuspitzungen von Amalarius' von Metz einstmals umstrittener, langfristig aber wirksamen Schrift De divinis officiis ${ }^{24}$, wie Ademar von Chabannes sie vornahm, hat ferner Regula Meyer Evitt jüngst dargelegt, wie gegenüber den Juden dann auch eschatologische Langzeitperspektiven und millenaristischer Eifer sich keineswegs ausschlossen, sondern nebeneinander bestehen und ineinander wirken konnten. ${ }^{25}$

22 J. Heil, Laborers in the Lord's Quarry: Carolingian Exegetes, Patristic Authority and Theological Innovation in 9th c. Exegesis, in: C. Chazelle and B. v. N. Edwards (Hg.), The Study of the Bible in the Carolingian Era, Turnhout 2003 (Medieval Church Studies 3), 75-95.

23 Heil, Agobard (s. Anm. 14), 39-76.

24 J. M. Hanssens, Amalarii episcopi liturgica omnia, Bd. 2, Rom 1949; zur Person vgl. K. Zechiel-Eckes, Florus von Lyon als Kirchenpolitiker und Publizist. Studien zur Persönlichkeit eines karolingischen „Intellektuellen“ am Beispiel der Auseinandersetzung mit Amalarius (835-838) und des Prädestinationsstreits (851-855), Stuttgart 1999.

25 R. Meyer Evitt, The Liturgical Anti-Judaism of the Medieval Prophet Plays, in: Richard Landes et al. (Hg.), The Apocalyptic Year 1000. Religious Expectation and Social Change 950-1050, Oxford 2003, 205-229. 
Die Verbindung zwischen dem Befund aus der Theologie- und Sozialgeschichte, wie bis hier skizziert, und den antijüdischen Momenten in der westlichen Reaktion auf die Zerstörung der Grabeskirche 1009 liefert Rodulf Glaber (985-1047), der erzählfreudigere Chronist aus Burgund. Rodulf schrieb in seiner bis etwa 1045 geführten Chronik die Zerstörung der Grabeskirche aus der Hand fatimidischen Kalifen al-Hāakim (985-1021) im „neunten Jahr nach der Jahrtausendwende" des Teufels zu, der sich dieses über die ganze Welt bekannte und von Pilgern zahlreich besuchte Ziel mit Bedacht und neiderfüllt ausgesucht habe. Dafür habe er sich „wie gewohnt" des jüdischen Volks bedient, dessen Vertreter in Orléans besonders zahlreich gewesen und noch arroganter als anderswo aufgetreten seien. Diese hätten dann einen aus Moutiers entflohenen Mönch mit Namen Robert, eher ein Vagabund als ein Pilger, angestiftet und ihm hebräisch geschriebene Briefe an den Kalifen mitgegeben. Darin sei die Warnung enthalten gewesen, dass, sofern er nicht unverzüglich die Grabeskirche zerstöre, die Christen bald alle seine Lande besetzen und ihn seiner Macht berauben würden. Also befahl, so berichtet Rodulf, der „Fürst von Babylon“ es auszuführen, auch die Kirche des hl. Georg in Ramle, vor dessen Macht die Sarazenen bislang zurückgeschreckt seien, sei damals zerstört worden. Der Kalif erscheint hier geradezu als Getriebener, die Urheberschaft dagegen wird den Juden zugewiesen.

Ohne dass Rodulf sagte, auf welche Weise dies geschehen sei, soll die Rolle der Juden bei alledem alsbald in der gesamten Christenheit bekannt geworden sein, und einmütig hätten sie entschieden, diese aus ihren Städten und Ländern zu vertreiben. So seien sie allenthalben zum Objekt des Hasses („universi odio habiti“), erschlagen, ertränkt, sonstwie getötet oder auch durch Selbstmord dahingestreckt worden. Nur wenige Juden sollen „in orbe ... Romano "überlebt haben, und die Bischöfe hätten daraufhin bestimmt, dass kein Christ fortan mit ihnen Umgang haben solle. Ausgenommen waren nach Rodulf jene Juden, die die Taufe begehrten und von allen jüdischen Riten abzulassen versprachen. Diese Leute aber waren, wie der Mönch sogleich unterstellte, wenig verlässliche Kandidaten und hatten nur aus Angst um ihr Leben und ob ihrer Liebe zu irdischen Gütern in die Taufe eingewilligt; sie würden, so die Prognose, alsbald zu ihrem alten Glauben zurückkehren. Der Mönch Robert habe nach seiner Rückkehr dann in aller Vorsicht versucht, Kontakt zu überlebenden Juden aufzunehmen, sei aber von einem ebenfalls zurückgekehrten Reisebegleiter entdeckt, gefangen genommen, verhört und schließlich hingerichtet worden. Fünf Jahre nach dem Ereignis erst sollen dann einzelne Juden wieder in den Städten aufgetreten sein, was nur billig gewesen sei, denn zu ihrer eigenen Verwunderung sollten sie als Zeugen ihres eigenen Unglaubens und des vergossenen Blutes Christi weiterleben. ${ }^{26}$

26 Rodulf III.24-25, 132f.; vgl. J. France, Rodulfus Glaber and French Politics in the Early Eleventh Century, in: Francia 16 (1989), 101-112; R. Landes, Rodolfus Glaber 
Rodulfs Bericht ist bemerkenswert, nicht nur, weil er mit der Bezeichnung des Kalifen als „Fürst von Babylon“ ein markantes Antichrist-Signal einsetzte, die am Ende erfolgte Wiederkehr der Juden in die Städte aber in gelehrter Anspielung auf das augustinische Lehrformular von der eschatologischen Unentbehrlichkeit der Juden aufzufangen und mit eigener Drastik des Ausdrucks umzuwerten verstand. Sein Bericht erscheint an dieser Stelle vom Fortschreiten der Zeit und dem Fortrücken unmittelbarer endzeitlicher Besorgnisse, also vom Streben nach Gewinnung von postapokalyptischer Normalität geleitet, weshalb Juden und Kalif als Täter wieder auf ein irdisches Maß zurückgeführt werden mussten, nur mit dem Teufel als immerwährendem Anstifter im Hintergrund, aber ohne Antichristen und andere Akteure des endzeitlichen Geschehens mehr auf dem Vordergrund der Bühne. ${ }^{27}$ Jenseits dieses Mühens um Gegenwartsbewältigung erscheint Rodulfs Bericht zutreffend im Kern und völlig entstellt in den Details. Diese Bewertung basiert freilich auf unabgesicherten Plausibilitätserwägungen, bietet aber den Vorzug, seinen Bericht nicht zur Gänze verwerfen zu müssen. Ich setzte voraus, dass Rodulf es nicht wagen konnte, seinem Publikum eine völlig aus der Luft gegriffene Geschichte vorzusetzen, seine Erzählung also mit Vorherwissen, Gehörtem und Möglichem korrespondieren musste.

Realistisch war danach, dass es in Orléans und anderswo bald nach dem Jahr $1000 \mathrm{zu}$ einer Verfolgung von Juden gekommen ist, wobei noch nicht gesagt ist, ob der Zusammenhang mit der Zerstörung der Grabeskirche in Jerusalem im Ursprung mehr als nur eine ungefähre zeitliche Koinzidenz war, die erst der Chronist kausal zuordnete. Ferner dürfte es den Tatsachen entsprechen, dass man die Juden vor die Alternative Taufe oder Tod stellte und diese teils aus Angst, aber ohne wirkliche Überzeugung darein einwilligten, andere dagegen wie wenige Jahrzehnte später beim ersten Kreuzzug im Rheinland den kollektiven Freitod wählten, ein Ausweg, den die gelehrten Autoritäten der Zeit mit Distanz beurteilten. Bekannt ist auch die Tendenz, die Urheber kosmischer Katastrophen in der eigenen Mitte zu suchen und dabei ohne besondere Anstrengungen zu überzeugenden, um nicht zu sagen autosuggestiven Schlüssen zu gelangen. ${ }^{28}$

Schließlich ist die Figur der Mönchs Robert weitgehend realistisch gezeichnet und war womöglich eine tragische reale Persönlichkeit, die ihre Ahnungslosigkeit mit dem Leben bezahlte: Der entlaufene Mönch, der pilgernde Mönch -

and the Dawn of the New Millennium. Eschatology, Historiography, and the Year 1000, in: Revue Mabillon N.S. 7 (1996), 57-77.

27 J. Fried, Endzeiterwartung um die Jahrtausendwende, in: $D A 45$ (1989), 381-473; vgl. ferner unten, Anm. 60.

28 J. Heil, Gottesfeinde - Menschenfeinde. Die Vorstellung von jüdischer Weltverschwörung, 13.-16. Jh., Essen 2006 (Antisemitismus: Geschichte und Strukturen 3), 175-204. 
das sind fraglos realistische Figuren, aber auch der dienstbare Pilger im Mönchsgewand, der allerlei Briefe und Nachrichten mit auf den langen Weg nach Osten nehmen konnte. Natürlich waren das im Falle jüdischer Auftraggeber dann keinerlei hebräisch geschriebenen Nachrichten an den kaum zureichend polyglotten Kalifen, eher doch die üblichen Anfragen in sakralrechtlichen Angelegenheiten der Gemeinden des Westens an die halachischen Autoritäten des Osten, wie sie bis zum Niedergang des Gaonats im Zweistromland (1038 ff.) und der Ausbildung autonomer Zentren jüdischer Gelehrsamkeit in den Ländern des Mittelmeerraums und im Norden an der Tagesordnung gewesen sein müssen. ${ }^{29}$ Das alles sind gerade einmal die Bruchstücke eines tragisch missverständlichen Geschehens, das der Chronist dann zu einem konsistenten und die ergangenen Verfolgungen legitimierenden Narrativ zusammengefügt hat. Gerade Orléans war ja, wie Rodulfs folgender Bericht über die in jenen Jahren in der Stadt „entdeckte Häresie“ erkennen lässt, ein Ort besonders verdichteter Endzeitwahrnehmung, und Häresien aller Art wurden, nach Erledigung der unmittelbaren endzeitlichen Unruhe der Jahrzehnte um das Millennium, in den folgenden Jahrhunderten zur bestimmenden Obsession der westlichen Kirche. ${ }^{30}$

Die ganze Geschichte gehört aber bei Rodulf in einen weiteren Kontext von gänzlich lokaler Erstreckung: Dem Bericht von der Rolle der Juden bei der Zerstörung der Grabeskirche geht jener vom skandalösen Handeln des Grafen Rainard von Sens (gest. 1055) voran. Nicht nur die Kirche und die Armen habe dieser heftig bedrückt, er sei auch ein Judaisierer gewesen ${ }^{31}$, der sich von seiner Umgebung habe „König der Juden“ nennen lassen. Was tatsächlich dessen Sympathien für die Juden und ihre Riten gewesen sein sollen ${ }^{32}$, bleibt im Report des Chronisten unklar und verlangte wohl auch nach keiner weiteren Klärung, denn es diente augenscheinlich nur als Fixpunkt zur Negativzeichnung des Grafen als Übeltäter. ${ }^{33}$ Letztlich erscheint Rodulfs ganzer Bericht von der Zerstörung der Grabeskirche dieser lokalen Episode nachgeordnet. Dabei gibt die Charakterisierung des Grafen keinerlei Anlass zu ernster Faktensuche, zumal die ansonsten ähnlichen Negativzeichnungen des Grafen bei anderen Autoren gerade auf das Motiv Juden verzichten. ${ }^{34}$ Danach besteht keinerlei Anlass zur Vermutung einer

29 A. Graboïs, The Use of Letters as a Communication Medium Among Medieval European Jewish Communities, in: S. Menache (Hg.); Communication in the Jewish Diaspora - the Pre-Modern World, Leiden 1996, 93-105; A. Grossman, Communication Among Jewish Centers During the Tenth to the Twelfth Centuries in: ebd. 107-125.

30 Rodulf III.26-27, 138-143; vgl. J. Fried, Das Mittelalter - Geschichte und Kultur, München 2009, $153 \mathrm{f}$.

31 Rodulf III.20 u. 23, 129, 133, passim.

32 Rodulf III.20, $128 f$.

33 Rodulf III.21-23, 128-133.

34 Chronicon S. Petri Vivi, hg. R.-H. Bautier et al., Paris 1979, 110f. 124. 
besonderen Förderung jüdischer Präsenz in der Stadt nach dem Vorbild des späteren bischöflichen Privilegs für Speyer (1084), wie Robert Chazan sie unternommen hat. ${ }^{35}$

Es ist ja auch, was Rodulf andernorts über das Zusammenwirken von Juden, Heiden und Häretikern zu berichten weiß, mehr inspiriert als informiert ${ }^{36}$ und zeigt dann doch nur, dass er und seine reforminspirierten Zirkel einige Leute in Orléans nicht mochten und ansonsten dankbar jedes umlaufende Gerücht aufgriffen. Daran mit Robert Chazan und Richard Landes sogleich die These vom Aufkommen und überhaupt der Existenz charakteristischer „apokalyptischer Häresien“ zu knüpfen, die mit Ikonoklasmus und Sakramentsverweigerung tatsächlich ausgesprochen jüdisch in ihrem Auftritt gewesen seien ${ }^{37}$, besteht also wiederum kein zwingender Anlass. Eher handelt es sich hier um das, was Richard I. Moore als die Kreation einer Häresie durch niemand anderen als ihre künftigen Überwinder beschrieben hat, ohne dass er seinerseits wirklich die Konsequenzen aus seinen Beobachtungen gezogen hätte ${ }^{38}$, nämlich dass hier die Inkriminierung womöglich eigenwilliger, aber kaum devianter Christen entlang streng dogmatischer Kriterien, zumindest keiner veritablen „Manichäer“, von Statten ging ${ }^{39}$, wie sie auch sonst häufig genug mit dem dienstbaren Stereotyp des Judaisierens persekutorisch ins Abseits gedrängt wurden. In jedem Fall leiden diese Analysen daran, dass sie hinsichtlich der Charakteristika angeblicher Häresien ohne Grund den tendenziösen Berichten ihrer Gegner glauben, die ihrerseits soziale Konflikte als dogmatische Angelegenheiten bemäntelten und sich von plakativen Anschuldigungen mehr Überzeugungskraft versprachen als vom subtilen Nachweis feiner dogmatischer Differenzen.

Dem ist hinzuzufügen, dass die Tatsache eines in wesentlichen Punkten zu Rodulfs Version analogen Berichts bei Ademar von Chabannes kaum mehr zur Ermittlung der tatsächlichen Vorkommnisse, sondern nur über das Vorhanden-

35 R. Chazan, Church, State, and Jew in the Middle Ages, New York 1980, 58-63; ferner Ders., Jews (s. Anm. 13), 71-75.

36 Rodulf, IV.5, 176.

37 R. Chazan, Initial Crisis for Northern European Jewry, in: Proceedings of the American Academy for Jewish Research 38/39 (1970/71), 114ff.; Landes, Massacres (wie Anm. 5), 105; Ders., The Birth of Heresy. A Millennial Phenomenon?, in: Journal of Religious History 24 (2000), 26-43.

38 R. I. Moore, The Birth of a Popular Heresy, London 1975, 92; ferner Ders., The Birth of Popular Heresy. A Millennial Phenomenon?, in: Journal of Religious History 24 (2000), 8-25; Ders., Heresy as Politics and the Politics of Heresy, 1022-1180, in: R. Mazo Karras et al. (Hg.), Law and the Illicit in Medieval Europe, Philadelphia 2008, 33-46.

39 R. I. Moore, Die erste europäische Revolution. Gesellschaft und Kultur im Hochmittelalter, München 2001, 162f., 175. 
sein eines mehr oder weniger unabhängig voneinander verwendeten Erzählstoffs und allseits eingespielter Deutungsmuster hergibt. Das wird besonders beim Blick auf Ademars Bericht vom Auftreten der „Manichäer" in Aquitanien und die stereotype Schilderung ihrer angeblichen Taten deutlich: sie hätten nicht nur Taufe und Kreuzverehrung abgelehnt, sondern auch Enthaltsamkeit nach außen vortäuschend „untereinander jedwede Ausschweifung (luxuriam) ausgeübt.“" Was die Juden angeht, so berichtete Ademar von der Zwangstaufe einiger Juden in Limoges und der Vertreibung der anderen. Ohne nähere Bezeichnung von Namen oder Orten, von wo solches seinen Ausgang genommen haben sollte, heißt es in der Folge, die "Juden des Westens" hätten 1009 zusammen mit den Sarazenen Spaniens Briefe mit der Nachricht eines bevorstehenden Angriffs der Christen in den Osten geschickt. Auch ein Adressat der Nachrichten wurde nicht genannt, er ist aber aus dem folgenden zu erschließen, insofern es „Nabuchodonosor“ (Nebukadnezar) „der Babylonier“ (auch dies ein Platzhaltername und Typ des Antichristen) gewesen sei, der darauf alle Christen zur Taufe habe zwingen wollen. Diesem Druck hätten die Christen mit Ausnahme des Patriarchen von Jerusalem nachgegeben. Auch seien, wie ausweislich der Edition Ademar erst in der Überarbeitung nachtrug und ihm offenbar auch nur später bekannt wurde, die Georgskirche in Ramle und die Grabeskirche in Jerusalem bis auf die Grundmauern zerstört worden. Ebenso seien die Sarazenen mit zehntausend Bewaffneten über das Kloster am Berg Sinai hergefallen und hätten es zerstören wollen. Allein die Geburtskirche in Bethlehem sei durch ein Wunder der Zerstörung entgangen. Ademars Geschichte nimmt sodann einen unerwarteten Verlauf: In der

40 Die Erwähnung der Häretiker ist dem noch zu besprechenden Bericht vom Zusammenwirken von Juden und Sarazenen nachgeordnet: Ademar von Chabannes, Chronicon III.49, hg. R. Landes, Turnhout 1999 (CCCM 129), 170; vgl. R. Landes, Relics, Apocalypse, and the Deceits of History. Ademar of Chabannes, 989-1034, Cambridge 1995, 175-177; D. F. Callahan, Ademar of Chabannes, Millennial Fears and the Development of Western Anti-Judaism, in: Journal of Ecclesiastical History 46 (1995), 19-35; Ders., The Cross, the Jews, and the Destruction of the Church of the Holy Sepulcher in the Writings of Ademar of Chabannes, in: M. Frasseto (Hg.), Christian Attitudes Toward the Jews in the Middle Ages. A Casebook, New York, 2007, 15-23; Ders., Al-Hakim, Charlemagne, and the Destruction of the Church of the Holy Sepulcher in Jerusalem in the Writings of Ademar of Chabannes, in: M. Gabriele et al. (Hg.), The Legend of Charlemagne in the Middle Ages. Power, Faith, and Crusade, New York 2008, 41-57; ferner M. Frasseto, Pagans, Heretics, Saracens, and Jews in the Sermons of Ademar of Chabannes, in: Ders. (Hg.), Heresy and the Persecuting Society in the Middle Ages. Essays on the Work of Robert I. Moore, Leiden 2006, 73-91. Zu den Juden dort vgl. M. Breuer, Un grand talmudiste à Limoges au XIe siècle: Rabbi Josph Bonfils, in: Bulletin de la Société Archéologique et Historique du Limousin 119 (1991), S. $61 f$. 
Folge seien der „König von Babylonien“ und sein Anhang von Bedauern um die Geschehnisse ergriffen worden, und so habe der Herrscher den Wiederaufbau der Grabeskirche angeordnet. Das sei ausgeführt worden, der Neubau danach freilich hinter der früheren Gestalt zurückgeblieben. ${ }^{41}$ An dieser Stelle gerät die Darstellung schon zur postapokalyptischen Revision einer implizit noch erkennbaren früheren Deutung, nach der das Zerstörungswerk den Täter als Antichristen entlarvte, ihm nun aber, sozusagen in der Figur eines ,Antichristus interruptus', den paradoxen Akt des Wiederaufbaus des Heiligtums zuschrieb, womit Ademar noch deutlicher als vor ihm Rodulf das Ausbleiben der vordem erwarteten endzeitlichen Erfüllung anzeigt.

Womöglich wollte man, was die Verfolgung der Juden zu Zeiten der Zerstörung der Grabeskirche angeht, Ademars und Rodulfs Erzählungen gänzlich als freie narrative Adaptionen abhandeln, würde diese Erzählung nicht in zentralen Punkten durch eine völlig unabhängige hebräische Quelle gestützt, die aus jüdischer Perspektive obendrein ein hinsichtlich der Geschehnisse anderes und weit dramatischeres Bild zeichnet. Robert Chazan hat sie zum Kernstück dessen gemacht, was er als ,initial crisis“ des nordeuropäischen Judentums verstand. ${ }^{42}$ Noch deutlicher hat Richard Landes diese Quelle im Verbund mit den Versionen bei Rodulf und Ademar zum Ausgangspunkt einer kritischen Neubetrachtung der Situation der europäischen Juden vor dem 1. Kreuzzug gemacht und daran auf die ihm eigene energische Weise die Folgerung geknüpft, die Geschichte des Antisemitismus müsse neu geschrieben werden. ${ }^{43}$ Nicht alle sind ihm darin gefolgt, gelegentlich aber auch nicht auf dem Stand der Diskussion. Jonathan Elukin hat zuletzt eine auf Differenzierung bedachte, ausgesprochen distanzierte Bewertung der Zeit vor 1096 vorgenommen und die integrativen Momente im jüdisch-christlichen Verhältnis der Zeit betont, allerdings ohne die verstörenden Berichte zu den Ereignissen der Jahre kurz nach 1000 überhaupt zur Kenntnis zu nehmen. ${ }^{44}$ Solch gravierende Unterschiede der Bewertungen lassen eine neuerliche Betrachtung der fraglichen Quellen angemessen erscheinen.

41 Ademar, Chronik III.47, 166f.

42 Chazan, Crisis (s. Anm. 37), 101-117; vgl. auch R. I. Moore, Anti-Semitism and the Birth of Europe, in: D. Wood (Hg.), Christianity and Judaism = Studies in Church History 29 (1992), 33-57.

43 Landes, Massacres (s. Anm. 5), 80.

44 J. Elukin, Living Together, Living Apart. Rethinking Jewish Christian Relations in the Middle Ages, Princeton 2007; vgl. auch Lotter, Vertreibung (s. Anm. 17), 41f; Ben-Shalom, Jewry (s. Anm. 1) 163; G. Nahon, Zarfat: Mittelalterliches Judentum in Nordfrankreich, in: Cluse, Europas Juden im Mittelalter, hier 223; Marcus, JewishChristian Symbiosis (wie Anm. 8), 456f. 
Der hebräische Text berichtet von einem Dekret (gsera) des Königs Robert von Zarfat (Frankreich) ${ }^{45}$ und seiner Frau auf Ratschlag ihrer Edelleute und Diener, wonach alle Juden, weil sie dem König den Gehorsam versagten, sich taufen lassen sollten oder umzubringen seien. Die Juden verweigerten sich dem, mit der Folge eines Blutbades. In der Normandie sei ein gewisser Jakob bar Jekutiel vor Herzog Richard getreten (der den königlichen Befehl zur Zwangstaufe offenbar für seinen Herrschaftsbereich aufzugreifen beabsichtigte) und habe ihm entgegnet, dass ,er keine Macht hat, Israel zur Aufgabe seiner Religion zu zwingen, es sei denn, der Papst von Rom ordnete das an. Wenn Du zustimmst, gehe ich dorthin, und danach magst Du tun, was er bestimmt." Darauf habe der Herzog ihn mit seiner Familie einkerkern lassen, dann aber unter Zurückhaltung eines seiner Söhne als Geisel zugestanden, dass Jakob zum Papst reise. In Rom angekommen, soll er zum Papst gelangt sein, sich vor ihm niedergeworfen und sich erklärt haben, woraufhin dieser sich eine Beratungszeit von fünfzehn Tagen ausbedungen, aber auch für freundliche Aufnahme Jakobs und seiner Familie gesorgt habe. Nach fünfzehn Tagen schließlich sei die Entscheidung gefallen und ein Gesandter des Papstes mit Brief und Siegel ausgesandt worden, woraufhin die Verfolgungen ein Ende nahmen. Jakob aber sei anschließend ehrenvoll in seine Heimat Lothringen entlassen worden. ${ }^{46}$

Die Diskussion um die Feindatierung des Textes ist ausgiebig geführt worden. Tatsächlich korreliert die hebräische Datierung zu 4767 a.M. (jud.) mit dem Lateinischen Jahr 1007 a.D., und nicht mit 1009/10 - aber allein schon Richard Landes Hinweis auf die vermutlich eine oder mehr Generationen später erfolgte Niederschrift lässt diese Differenz zunächst unerheblich erscheinen. ${ }^{47}$ Und natürlich bieten die lateinischen und hebräischen Berichte mit ihren Einzelheiten praktisch kaum Deckung, aber sie erzählen verwandte Vorgänge, zumal solche, die sich analog ereignet und aus verschiedenen Blickwinkeln (später) aufgenommen worden sein können.

Nach dem anonymen Bericht zu Jakob bar Jekutiel, der anschließend auf Einladung des Grafen Balduin von Flandern zehn Jahre in Arras lebte und von

45 Zarfat ist Ov. 1,20 entnommen und unternimmt eine Verortung von Francia ähnlich der Benennung von Aschkenas als biblisch verbürgtes Land im Norden; vgl. Malkiel, Ashkenaz (s. Anm. 13), IX.

46 Hg. A. Habermann, Sefer gezerot aschkenaz we zarfat (hebr.), Jerusalem 1945, 19ff.; vgl. S. Schwarzfuchs, Chroniques hebraiques du XIeme siècle, in: Evidences 6 (1954), Übers. 36f.; R. Chazan, Medieval Jewry in Northern France. A Political and Social History, Baltimore etc. 1973, 11-15; K. R. Stow, The "1007 Anonymus" and Papal Sovereignity. Jewish Perception of the Papacy and Papal Policy in the High Middle Ages, Cincinnati 1984 (Hebrew Union College Annual Suppl. 4), 26f. 67-71 (Parma, de Rossi 563); Golb, Jews (s. Anm. 1), 547-550 (Übers.).

47 Landes, Massacres (s. Anm. 5), $90 \mathrm{f}$. 
seinen Söhnen in Reims bestattet wurde, also wenigstens zehn Jahre nach den Ereignissen aufgezeichnet sein will, kann wenig Zweifel bestehen, dass es vor 1010 zur Verfolgung von Juden gekommen ist, an verschiedenen Orten in Frankreich und in abgeschwächter Form dann womöglich eben auch in Mainz. Unklar bleibt, inwieweit diese Ereignisse ihre Ursache in einem allgemein endzeitlich aufgeheizten Klima hatten, ebenso ob, wie bei Rodulf und Ademar berichtet, Vorgänge im Heiligen Land der Auslöser für das Geschehen gewesen sind. Für beides gibt der hebräische Anonymus keinen Anhalt; er schreibt den Auslöser alleine der Willkür des Königs und dem Unmut des Christenvolks über die Anwesenheit der Juden in ihren Landen zu. Dass wirklich, wie der Bericht zu Jakob ben Jekutiel behauptet, Robert II. von Frankreich und sein Beraterkreis eine Initialrolle zur Verfolgung der Juden gespielt hätten, ist zumindest nicht auszuschließen, aus einer einzelnen Quelle aber auch nicht sicher zu belegen.

Bemerkenswert immerhin ist die Rolle, die der Bericht zu Jakob bar Jekutiel dem Papst, wohl Johannes XVIII., zuweist. Die hier überraschend früh anklingende Sicut Judaeis-Tradition ist ansonsten erst für Callixt II. nachweisbar, das ist 1119-1124, also mehr als hundert Jahre nach den in der Erzählung zu Jakob verhandelten Ereignissen. ${ }^{48}$ Im Grunde sind zumindest seit Gregor dem Grossen ausgangs des 6. Jahrhunderts bis auf Alexander II. (1061-1073) keine nennenswerten Aktivitäten des römischen Stuhls für die Juden zu registrieren. Ademar von Chabannes stellte Benedikt VIII. (1012-1024) gar als entschiedenen Gegner der Juden vor, der die Urheber eines Erdbebens in Rom am Karfreitag des Jahres 1018 in der Synagoge ausgemacht habe, wo sie den Gekreuzigten verhöhnten und woraufhin der Papst, mit dem Ergebnis des Abklingens der Erdenwallung, die Anführer habe hinrichten lassen. ${ }^{49}$ Angesichts des frühen Anklangs des Konzepts päpstlichen Judenschutzes beim „1007 Anonymus“ ist es nachvollziehbar, dass man der Authentizität des Berichts überhaupt misstraute und ihn allein schon deswegen für ein Produkt des 12. Jahrhunderts gehalten hat. ${ }^{50}$ Freilich ist die späte Überlieferung eines Textes gerade im Fall der disparaten Überlieferungslage jüdischer Quellen des hohen Mittelalters kein Anhaltspunkt zur Datierung und kaum ein Argument gegen eine frühere Datierung des überlieferten Stoffes. Und es unterscheidet sich der Text zu Jakob bar Jekutiel doch wesentlich von anderen späteren jüdischen Konstruktionen angeblich früherer Ereignisse. Denn

48 Vgl. auch Chazan, Jewry (s. Anm. 46), 41f.; S. Simonsohn, The Apostolic See and the Jews - History, Toronto 1991, 42-45; vgl. auch G. Gresser, Die Synoden und Konzilien in der Zeit des Reformpapsttums in Deutschland und Italien von Leo IX. bis Calixt II. 1049-1123, Paderborn 2006.

49 Ademar III.52, 171.

50 Stow, Anonymus (s. Anm. 46); Ders., The Avignonese Papacy, or: After the Expulsions, in: Cohen, Witcheraft (s. Anm. 5), hier 276-278 mit Anm. 5-6. 
es fehlen dem Bericht alle narrationsfreudigen, phantastischen Elemente, etwa die leicht als gegenwartsgeleitete Apologie zu entschlüsselnde Behauptung altehrwürdiger Abkunft der Juden an einzelnen Orten, wie sie für andere jüdische Konstruktionen der Vergangenheit so bezeichnend ist. ${ }^{51}$ Der Bericht erscheint, ohne besondere Not, ausgesprochen akkurat in der Darstellung von Einzelheiten und bietet insofern inneren Anhalt, ihn als im Kern glaubhaft zu bewerten. Es bestand obendrein im 12. Jahrhundert, zumal nach der Pogromwelle im Gefolge des 1 . Kreuzzugs 1096, auch wenig Anlass, so detailgetreu eine Geschichte zum fernen Anfang des 11. Jahrhunderts zu erzählen, es sei denn, sie hätte sich ereignet und als eigener Erzählstrang behaupten können. Es haben sich aus der Zeit vor $1096 \mathrm{ja}$ auch andere jüdische Erzählungen erhalten, die ähnlich akkurat zu Einzelheiten, aber nur schwer in einen Kontext einzubetten sind, etwa zu Le Mans 992 oder Speyer 1084. ${ }^{52}$ So muss auch Jakobs Reise nach Rom nicht einfach erfunden gewesen sein, und Rom war angesichts zumindest unentschiedener, wenn nicht feindseliger Könige, Herzöge, Bischöfe und Grafen zumindest keine abwegige Adresse bei der Ansuche um Schutz: in Rom bestand eine kulturell wie ökonomisch prosperierende Gemeinde, die Tore zu öffnen wusste und - nebenbei erwähnt - in diesen Jahren auch qualifiziertes Personal an die Gemeinden am Rhein zu entsenden im Stande war..$^{53}$

Für die Authentizität des Berichts zu Jakob bar Jekutiel schließlich spricht die bislang wenig beachtete, aber so prominent gezeichnete Rolle, die der Normannenherzog Richard bei der Anbahnung des Kontakts zum Papst, demnach Johannes XVIII. (1004-1009), gespielt haben soll. Dieses Detail erscheint, in den weiteren Zeithorizont eingebettet, höchst aufschlussreich. Denn für einen nur wenige Jahre später liegenden Zeitpunkt, 1017/18, ist tatsächlich die Aufnahme unmittelbarer Kontakte zwischen dem Papsttum in Person Benedikts VIII. (1012-1024) und normannischen Söldnern verbürgt. Ademar wie Rodulf beziehen das auf die Zeit Herzog Richards II. von der Normandie (996-1026), der mit jenem im Bericht zu Jakob bar Jekutiel genannten Herzog gleichen Namens identisch sein dürfte. ${ }^{54}$ Dass, wie der hebräische Bericht behauptet, ausgerechnet der Normannenherzog, wenn auch widerwillig, den Juden den Weg zum Papst gewiesen haben könnte, erscheint insofern zumindest plausibel. Obendrein gibt es Anhaltspunkte, dass Normannen, eher Söldner als Jerusalem- und Gargano-

51 Vgl. J. Heil, Jenseits von „History and Memory“. Spuren jüdischer Geschichtsschreibung im Mittelalter, in: Zeitschrift für Geschichtswissenschaft 55 (2007), 989-1019.

52 R. Chazan, The Persecution of 992, in: Revue des Études Juives 129 (1970), 217-221; Heil, Spuren (s. Anm. 51), 1008.

53 Chazan, Jewry (s. Anm. 46); M. Toch, The Formation of a Diaspora. The Settlement of Jews in the Medieval German Reich, in: Aschkenas 7 (1997), 55-78.

54 Rodulf Glaber, Hist. III.3, 97f.; Ademar, Chronik III.55, $173 \mathrm{f}$. 
Pilger, schon kurz vor dem Jahr 1000 in Italien präsent waren und sich dabei in Kontakt zu den Päpsten begeben haben, die ihnen zusammen mit den langobardischen Fürsten eine Rolle in den süditalienischen Auseinandersetzung mit Sarazenen und Griechen übertrugen, und das schon vor dem zweiten apulischen Aufstand gegen die Byzantiner 1016/17. Nicht nur die fernab von Rom wirkenden Chronisten Ademar und Rodulf, sondern auch Berichterstatter aus dem Süden Italiens wie die Historia Normannorum des Amatus von Montecassino, die Annales Casinenses oder Romulad von Salerno geben Hinweise auf die Präsenz normannischer Söldner, die bis auf oder knapp über das Jahr 1000 zurückreichen. ${ }^{55}$

Irritierend ist dagegen noch etwas anderes: dass die Itinerare des Jakob bar Jekutiel beim hebräischen Anonymus und des vor Herzog Richard fliehenden Normannen Rodulf, wie der gleichnamige Chronist es (hier ohne Bezug auf die Juden) überliefert, nahezu identisch berichtet werden: beide verließen die Normandie in höchster Not und trugen ihre Sache dem Papst vor. Für die Annahme einer narrativen Abhängigkeit der einen von der anderen Quelle gibt es aber weder Anhalt noch Anlass. Doch auch die Version bei Rodulf bestätigt, dass für Flüchtlinge aus der Normandie Rom und der Papst als naheliegende Anlaufziele galten. Insofern kann er zur Unterstützung der Glaubhaftigkeit des Berichts zu Jakob bar Jekutiel und seiner Mission zum Papst angeführt werden.

Eine Gesamtbetrachtung der drei maßgeblichen Quellen zu den Ereignissen der Jahre nach 1000 scheint mehr Fragen aufzuwerfen, als sie löste. Bei näherem Hinsehen lässt sich das Gewirr annähernd ordnen: Die zwei christlichen und die jüdische Erzählung beziehen sich offensichtlich auf denselben Ereignisrahmen,

55 Maßgeblich ist noch immer die umfassende Analyse unterschiedlicher Quellenzeugnisse durch Hartmut Hoffmann, Die Anfänge der Normannen in Süditalien, in: Quellen und Forschungen aus italienischen Archiven und Bibliotheken 47 (1969), 95-144; dazu auch J. Deér, Papsttum und Normannen. Untersuchungen zu ihren lehnsrechtlichen und kirchenpolitischen Beziehungen, Köln 1972, 1. 93; kritisch J. France, The Occasion of the Coming of the Normans to Italy, in: Journal of Medieval History 17 (1991), 185-205; zuletzt J. Becker, Graf Roger I. von Sizilien. Wegbreiter des normannischen Königreichs, Tübingen 2008 (Bibl. des Deutschen Historischen Instituts in Rom 117), 32f.; vgl. ferner Radulf, Chronik III.1-3, 94ff., mit Anm. 7; sowie E. Johnson, The Process of Norman Exile into Southern Italy, in: L. Napran (Hg.), Exile in the Middle Ages. Selected Proceedings from the International Medieval Congress, University of Leeds, 8-11 July 2002, Turnhout 2004, 29-38; J.-M. Martin, Les Normands et le culte de saint Michel en Italie du sud, in: P. Bouet et al. (Hg.), Culte et pèlerinages à saint Michel en occident. Les trois monts dédiés à l'archange, Rom 2003 (Coll. de l'École de Rome 316), 341f.; P. Bouet, Pour quelles raisons les Normands ont-ils émigré en Italie du Sud aux XIe et XIIe siècles?, in: Les dossiers d'archéologie 299 (2005), 6-11, G. A. Loud, The Latin Church in Norman Italy, Cambridge 2007, $60 f$. 
geben aber nicht nur unterschiedliche Perspektiven wieder, sondern setzen jeweils eigene Akzente und warten mit bemerkenswert verschiedenen Einzelheiten auf. Im Grunde harmonieren zumindest Ademar und Rodulf in der Struktur des Erzählten: Beide berichten von den Ereignissen im Heiligen Land und setzen es $\mathrm{zu}$ Vorkommnissen in ihrer eigenen Umgebung in Beziehung. Als Initiatoren und Akteure vor Ort treten die lokalen Bischöfe und das Kollegium der Bischöfe als Repräsentanten der Kirche auf, bei Rodulf ergänzt um das Moment häretischer Bewegungen vor Ort, das bei Ademar fehlt. Dagegen verschiebt der Bericht zu Jakob bar Jekutiel den Akzent auf die weltliche Seite. Dessen Überlieferung alleine rückt König Robert II. ins Zentrum des Geschehens und weist ihm die Rolle des Initiators der antijüdischen Aktionen zu, der erst im Papst einen entschiedenen Widersacher findet. Die anderen Bischöfe, die bei Ademar und Rodulf so bestimmend in ihrem Handeln erscheinen, spielen im hebräischen Bericht keine Rolle, ebenso wenig die christlichen Häretiker. Wer welchen Anteil am Geschehen genommen hat, wird sich danach kaum mit Bestimmtheit ermitteln lassen. Die Bewertung wird hier aber eher additiv als komparativ ansetzen müssen. Denn es ist kaum anzunehmen, dass Jakob, der von den Bischöfen nichts erwarten und sie gar nicht erst in den Blick nehmen musste, den König, dessen Position sehr wohl Anlass zu Erwartungen gegeben haben könnte, ganz zu Unrecht als Urheber der Gewalt gegen Juden angesehen hätte. Es gibt ferner keinen Grund für die Annahme, dass die durch Ademar und Rodulf berichteten Ereignisse in Frankreich nicht durch das Handeln der Bischöfe vor Ort bestimmt gewesen seien. Ademars und Rodulfs Darstellungen mögen hinsichtlich der Akteure und besonders der Rolle des Königs provinziell verengt und dafür um so stärker einer kosmisch-apokalyptischen Gegenwartsbestimmung verpflichtet erscheinen. Aber sie müssen deswegen hinsichtlich der Fakten nicht unergiebig sein, sondern können Momente aus einem Geschehen berichten, dessen weitere politische Dimensionen allein der von ihnen unabhängige Bericht zu Jakob bar Jekutiel andeutete.

Entscheidend für die Beurteilung des Berichts Jakob und seiner Aussagekraft in Hinsicht der auf christlicher Seite kolportierten Versionen ist aber dessen Beschränkung auf die Juden Frankreichs und ihre Beziehung zu König und Fürsten. Von der Zerstörung der Grabeskirche berichtete der Anonymus nichts, und so bieten allein die geschilderten Vorgänge in Frankreich die Schnittmenge zwischen christlicher und jüdischer Überlieferung. Die Ereignisse in Frankreich und Deutschland zwischen 1007 (?) und 1012 können an sich zureichend aus dem Widerspruch zwischen der „hermeneutischen“ und der realen Präsenz von Juden, der auf prekäre Weise ungeklärten theologisch-rechtlichen Grundlage jüdischer Existenz in christlicher Umgebung und dem umfassend vorhandenen Gewaltpotential, erklärt werden. Allein die christlichen Chronisten des Westens haben dann, übrigens ganz im Unterschied zu den christlichen und muslimischen 
Autoren des Ostens ${ }^{56}$, einen Zusammenhang zu den Vorgängen im Heiligen Land hergestellt, allem Anschein nach aber post eventum und in dramatisierendlegitimatorischer Absicht, wohl mit dem Ziel, den zwischenzeitlich als sakramental wie rechtlich problematisch erachteten Akt der erfolgten Zwangstaufe narrativ zu bemänteln. ${ }^{57}$

Wo bis hier zunächst keine der drei verfügbaren Quellen zu den Ereignissen in Frankreich eingangs des 11. Jahrhunderts zureichend akkurat erscheint, um ihr eindeutig den Vorzug gegenüber den anderen zu geben, stellt sich auch die Frage der Datierung der Ereignisse neu. Rodulf ordnet sie dem Jahr 1009 zu, Ademar bietet überhaupt keine Zeitangabe für die beschriebenen Geschehnisse ${ }^{58}$, während der Anonymus zu Jakob bar Jekutiel sich auf 1007 (4767) festlegt. ${ }^{59}$ Nach allem folgt die Datierung der Ereignisse in Frankreich zu 1009 bei Rodulf jedoch aus der narrativen Bindung an die Vorgänge im Osten sowie seiner Beschäftigung mit der Figur des Grafen Rainard von Sens, während die hebräische Quelle von diesen Kriterien unbeeindruckt mit 1007 womöglich das tatsächliche Jahr der Verfolgung durch Fürsten und Bischöfe im Westen bietet. Der Anonymus mit dem Bericht von Jakobs Romfahrt wäre dann nicht nur ein weiterer Beleg für die frühe Präsenz der Normannen in Italien, sondern auch für die Intensität der Vermittlung römischer Standards in Theologie und Recht nach der Normandie, deren wenigstens grobe Kenntnis selbst die dortigen Juden erreicht und sie zu selbstbewusstem Auftreten ermuntert hätte.

56 Die östlichen Quellen stimmen bei aller Unterschiedlichkeit darin überein, dass es ein österliches Feuerwunder gewesen sei, das den irritierten Kalifen zur Zerstörung der Grabeskirche veranlasst habe (Übersicht bei M. Canard, La destruction de l'église de la résurrection par le caliphe Hakim et l'histoire de la descente du feu sacré, in: Byzantion 25 [1965], insb. 20-28); dabei mag man im plötzlichen Handeln des Kalifen gerade ob der lang zurückreichenden Tradition des Wunders wiederum eine Reaktion auf endzeitliche Zuspitzungen auf christlicher Seite erkennen, was in der Sache dann aber immer noch von den im Westen kolportieren Versionen deutlich verschieden ist.

57 Vgl. Chazan, Crisis (s. Anm. 37), 107; Landes, Massacres (s. Anm. 5), 91f. besteht im Gegenteil darauf, dass eine plausible Deutung des Geschehens in Frankreich nur als Reaktion auf die Zerstörung der Grabeskirche und die Kenntnis davon möglich sei. Dass auch der „hebräische Text nur Sinn mache, wenn so abgeleitet“, ist aber nicht zwingend und lässt die Frage offen, warum dieser dann die Jerusalemer Ereignisse nicht selbst berichtete; vgl. auch Landes, Relics (s. Anm. 40), 295-308; Stow, Papacy (s. Anm. 50), 277f., Anm. 6; ferner Lotter, Vertreibung (s. Anm. 17), 41-43; sowie R. L. Wolff, How the News was Brought from Byzantium to Angoulême, or: The Pursuit of a Hare in an Ox Cart, in: BMGS 4 (1978), 139-189.

58 Rodulf, Chronik, III.24, 132; Ademar, Chronik, III.47, 166; die Datierung zu 1010 bei Callahan, Charlemagne (wie Anm. 40), ist der modernen Edition entnommen.

59 Stow, Anonymus (s. Anm. 46), 67 (hebr., ms. Parma, de Rossi 563); Golb, Jews (s. Anm. 1), 457. 
Mit dieser Differenzierung zwischen den lateinischen Chroniken und dem hebräischen Bericht soll keineswegs die Intensität und die Breite der endzeitlichen Bewegungen um das Jahr 1000 in Frage gestellt werden. ${ }^{60}$ Dass Rodulf wie auch Ademar das lokale Geschehen anschließend in einem kosmischen Zusammenhang ordneten, kann gar als Beleg für die Intensität des Erlebten gelten. ${ }^{61}$ Allerdings begehen moderne Historiker dann womöglich auch den Fehler, jedwedes Ereignis der Zeit in diesem Kontext zu deuten und ihre eigene Übersicht über die Vorgänge in Ost wie West den Zeitgenossen zuzuschreiben. Dabei übersehen sie, dass diese nur allmählich zu einem Bild gelangten, in dem das eine sich zum anderen fügte. Jedenfalls besteht kein Anlass, die Vorgänge nicht zunächst in ihrem westeuropäischen Zusammenhang zu betrachten, wie es der hebräische Anonymus tut, und die Verbindung zu den Ereignissen im Osten als spätere Zutat der christlichen Interpreten zu deuten.

Bei allen Unschärfen, die die verfügbaren Quellen aufweisen, wird in jedem Fall deutlich, dass es in der kritischen Phase des 11. Jahrhunderts nirgendwo das Königtum war, das jüdischer Existenz eine stabile rechtliche und faktische Grundlage zu geben im Stande oder auch nur gewillt war. Und im Grunde sollte der Aufschwung, den jüdischen Leben allerorten in Europa bis ins 13. Jahrhundert nahm ${ }^{62}$, nicht darüber hinwegtäuschen, dass von Herrscherseite die Juden in weiten Teilen Europas auch in der Folgezeit keinerlei sichere Rechtstitel entgegennehmen konnten. In Frankreich und England fanden Juden überhaupt nur für einen kurzen Zeitraum zwischen dem beginnenden 12. Jahrhundert und der

60 R. Landes, Lest the Millenium be Fulfilled. Apocalyptic Expectations and the Pattern of Western Chronography, 100-800 CE., in: W. Verbeke et al. (Hg.): The Use and Abuse of Eschatology in the Middle Ages, Löwen 1988 (Mediaevalia Lovaniensia I.15) 137-211; Fried, Endzeiterwartung (s. Anm. 27), 381-473; R. Landes, Millenarismus absconditus. L'historiographie augustinienne et le millenarisme du haut moyenage jusqu'en I'an mil, in: Le Moyen-Age 98 (1992), 355-377; J. Fried, Die Endzeit fest im Griff des Positivismus? Zur Auseinandersetzung mit Sylvain Gouguenheim, in: HZ 275 (2002), 281-321; B. Kühnel, The End of Time in the Order of Things. Science and Eschatology in Early Medieval Art, Regensburg 2003, 18f. 255f.; ferner Landes et al. (Hg.), The Apocalyptic Year 1000; zur Gegenposition vgl. etwa S. Gouguenheim, Les fausses terreurs de l'an mil. Attente de la fin des temps ou approfondissement de la foi?, Paris 1999, 93f.

61 Vgl. J. Heil, „nos nescientes de hoc velle manere“. Timeless End, or: Approaches to Reconceptualizing Eschatology after 800 = AM 6000, in: Traditio 55 (2000), 73-103, bes. $97 \mathrm{f}$.

62 Heil, Enmity (s. Anm. 10). 
Mitte des 13. Jahrhunderts eine stabile Grundlage und prosperierten auch und gerade in intellektuell-kultureller Hinsicht, aber ohne rechtliche Absicherung von der Art, wie sie im Herrschaftsgebiet der salischen Kaiser seit dem Ausgang des 11. Jahrhunderts und dann durch die Aufnahme der Juden in den allgemeinen Landfrieden durch Kaiser Heinrich IV. 1103 praktiziert wurde. Die erste Vertreibung 1181 aus den französischen Kronlanden, die Talmudverbrennung 1242 in Paris und die Vertreibung der Juden aus England 1290 bezeichnen bereits Krisen und Ende der prosperierenden mittelalterlichen jüdischen Kultur in den westlichen Randzonen Europas. ${ }^{63}$

Der Blick auf die unsicheren Verhältnisse zu Beginn des 11. Jahrhunderts gibt dann Anlass zu einer Neueinschätzung der herrschaftsrechtlichen Integration der Juden im römisch-deutschen Reich und ihres Effekts, die noch vor dem 1. Kreuzzug 1096 mit dem Speyerer Privileg von 1084 einsetzte, mit der Aufnahme der Juden in die Landfriedensgesetzgebung Heinrichs IV. im Jahr 1103 einen ersten Höhepunkt erreichte und sich dann in der staufischen Judenpolitik des 12./13. Jahrhunderts - trotz aller Defizite - voll entfaltete und jüdischen Gemeinden und jüdischer Kultur zu unvergleichlicher Höhe verhalf, wenigstens bis 1298 (Rintfleisch-Pogrome). Die Ausbildung eines spezifischen Judenregals, also die Bereitschaft, den Schutz der Nichtchristen in den Kanon herrscherlicher Pflichten zu erheben, hat eine dauerhafte Entwicklung jüdischen Lebens im römisch-deutschen Reich erst möglich gemacht und auf rechtlicher wie sozialer Ebene eine Basis für das Überdauern der Minderheitenkultur selbst in den Momenten extremer Anfechtungen während des späten Mittelalters und der Frühneuzeit geschaffen. Der 1084/1090 geformte Modus königlichen Judenschutzes hat dann auch in den Osten hinein vorbildhaft gewirkt, etwa im Statut von Kalisz 1264 und seiner Bestätigung hundert Jahre später. ${ }^{64}$ In den Königreichen Frank-

63 Vgl. D. Abulafia, Der König und die Juden - Juden im Dienst des Herrschers, in: Cluse, Europas Juden im Mittelalter, 60-71; Nahon, Zarfat 223; ferner W. C. Jordan, The French Monarchy and the Jews, Philadelphia 1989, 252ff.; R. Mundill, England's Jewish Solution. Experiment and Expulsion, 1262-1290, Cambridge 1998; G. Dahan (Hg.), Le brûlement du Talmud à Paris, 1242-1422, Paris 1999; ferner P. Skinner (Hg.), Jews in Medieval Britain: Historical, Literary and Archaeological Perspectives, Woodbridge 2003.

64 Vgl. S. Netzer, Wanderungen der Juden und Neusiedlung in Osteuropa, in: M. Brocke (Hg.), Beter und Rebellen. Aus 1000 Jahren Judentum in Polen, Frankfurt am Main 1983, 33-49; W. Schich, Zum Problem der Juden in der frühen deutschrechtlichen Stadt im östlichen Mitteleuropa, in: S. Jersch-Wenzel, (Hg.), Deutsche, Juden, Polen. Ihre Beziehungen von den Anfängen bis ins 20. Jahrhundert, Berlin 1987, 87ff.; C. Lübke: „... und es kommen zu ihnen ... Mohammedaner, Juden und Türken ...“. Die mittelalterlichen Grundlagen des Judentums im östlichen Europa, in: M. Hausleitner et al. (Hg.), Juden und Antisemitismus im östlichen Europa, Berlin 1995, 
reich und England dagegen hatte jüdisches Leben über das 13./14. Jahrhundert hinaus keinen Bestand; die herrscherlichen Judenstatuten von 1230 (Frankreich) und 1275 (England) waren ganz auf den fiskalischen Nutzen hin geschrieben und können kaum im Sinne von Privilegierung mit Zusicherung von Autonomie gelesen werden. ${ }^{65}$ Die Ursache für das gewaltsame Ende der jüdischen Geschichte in England und Frankreich dürfte daher zu wesentlichen Teilen im noch eigens zu erklärenden, im Effekt aber markanten Ausbleiben einer bindenden Rechtstradition königlichen Judenschutzes zu suchen sein.

Kehren wir noch einmal nach Jerusalem zurück. Mit dem Abflauen millenaristischer Bewegungen nach der Mitte des 11. Jahrhunderts hatte sich die Brisanz des Ortes nicht erledigt. Sie klingt auch in der Folgezeit nach. Jerusalem war nicht nur ein immer wieder besuchtes Pilgerziel, mehrheitlich durch Christen, aber auch durch Juden, sondern ein Ort konkreter, um nicht zu sagen, unerbittlicher eschatologischer Konkurrenz, und das auf Dauer.

Gleich mit 12.000 Anhängern soll sich R. Elijahu ben Menachem aus Le Mans im Jahr 1040 nach Jerusalem aufgemacht haben. ${ }^{66}$ Die Zahl ist fraglos symbolisch übertrieben, das behauptete Ereignis aber an sich aussagekräftig, auch wenn statt der genannten Zahl nur zwölf oder dreizehn Anhänger Elijahus mit ihrem Meister aus Frankreich abgezogen wären. Das abwartende Nebeneinander in der Gegenwart bot sich auf die Zukunft hin mit konträren Vollendungserwartungen kompromisslos dar. Selbst unter den heilsgeschichtlich ungünstigen Vorzeichen umfassender und deswegen eigentlich um so verstörender christlicher Dominanz über das Heilige Land in den Jahren 1099 bis 1187 gelang es dem Reisenden Benjamin von Tudela (gest. ca. 1173), seinem Bericht von den biblischen Königsgräbern auf Zion eine tröstliche Note einzuschreiben und die Christen samt ihrem Oberhaupt, dem Patriarchen, als heilsgeschichtliche Stümper zu zeichnen: rein gar nichts hätten die Christen in all ihrer Macht vermocht, und Gott habe ihnen mit starken Zeichen den Zugang zu den Zeugen der Geschichte Israels verwehrt, so lautete Benjamins Botschaft.

Benjamin zufolge befanden sich am Berg Zion die „Gräber vom Hause David sowie der Könige, die ihm gefolgt sind“, aber ihre genaue Lage sei unbekannt, denn vor 15 Jahren sei die Kirche dort eingestürzt, und der Patriarch habe befoh-

39-57; H.-D. Löwe, Die Juden in Krakau-Kazimierz bis zur Mitte des 17. Jahrhunderts, in: M. Graetz (Hg.): Schöpferische Momente des europäischen Judentums, Heidelberg 2000, 271-320.

65 Vgl. auch Chazan, Jewry (s. Anm. 46), 11. 27.

66 Heil, Gottesfeinde (s. Anm. 28), 422. 
len, aus den Trümmern eine neue Kirche zu errichten. Bei den Arbeiten hätten zwei der Bauleute den Eingang zu einer Höhle mit einer anschließenden großen Grabkammer freigelegt, „die auf Marmorsäulen gebaut und mit Gold und Silber überzogen war. Davor waren ein goldener Tisch, ein Szepter und eine Krone“ den Arbeitern war also zufällig der große Durchbruch gelungen: „Das war das Grab des Königs David. Zu seiner Linken befand sich das Grab des Königs Schlomo, dann folgten der Reihe nach die Gräber aller Könige von Juda“, ferner „Kisten von denen niemand weiß, was in ihnen ist.“ Doch als die Männer in die Höhle eintreten wollten, „blies ihnen vom Eingang der Höhle plötzlich ein heftiger Wind entgegen und traf sie so, dass sie wie tot auf die Erde fielen und bis zum Abend liegen blieben."

Dann habe ihnen ein anderer Wind eine menschliche Stimme herangetragen und sie aufgefordert, den Ort sofort zu verlassen. Sie seien darauf zum Patriarchen gelaufen, der in seiner Not den frommen Rav Abraham al-Qustantini um Auskunft gerufen hätte. Dieser habe bestätigt, dass es sich um die Gräber der Könige Judas handele. Angesichts der Angst der Arbeiter, dort auch nur einmal mehr noch hineinzugehen, habe der Patriarch aber nicht mehr vermocht, als die Verschließung der Höhle zu befehlen. ${ }^{67}$ In all seiner Macht also blieb dem Patriarchen am Ende nur übrig, das unbequeme Geheimnis versiegeln zu lassen.

Nach gleichem Muster ist auch Benjamins Bericht vom Besuch bei den Patriarchengräbern in Hebron gezeichnet: die Christen verehrten in ihrer naiven Frömmigkeit einfach den falschen Ort, während nur ihm, dem Juden Benjamin, der Zugang zu den eigentlichen Gräbern vergönnt gewesen sei. ${ }^{68}$ So viel Selbstbewusstsein darf dann, angesichts der Geschichte des 11. und 12. Jahrhunderts, vielleicht schon erstaunen. Es war aber dies das Elixier, das ein hoffnungsfrohes Weiterleben ermöglichte.

Das Verfahren, mit der Narration die eigene Heilsgewissheit zu behaupten und damit zugleich jene der anderen Seite effektreich zu bestreiten, war freilich

67 Benjamin von Tudela, Buch der Reisen, in: S. Schreiner (Hg.), Jüdische Reisen im Mittelalter, Köln 1998, 44-47; vgl. O. Limor, The Origins of a Tradition: King David's Tomb on Mt. Zion, in: Traditio 44 (1988), 453-462; J. Shatzmiller, Jews, Pilgrimage, and the Christian Cult of Saints: Benjamin of Tudela and his Contemporaries, in: A. C. Murray (Hg.), After Rome's Fall. Narrators and Sources of Early Medieval History. Essays presented to Walter Goffart, Toronto 1998, 337-347; A. Kuyt, Die Welt aus sefardischer und ashkenazischer Sicht: Die mittelalterlichen hebräischen Reiseberichte des Benjamin von Tudela und des Petachja von Regensburg, in: X. von Ertzdorff et al. (Hg.), Erkundung und Beschreibung der Welt: Zur Poetik der Reiseund Länderberichte, Amsterdam 2003, 211-231; D. Jacoby, Benjamin of Tudela and his 'Book of Travels', in: K. Herbers et al. (Hg.), Venezia, incrocio di culture. Percezioni di viaggiatori europei e non europei a confronto, Rom 2008, 135-164.

68 Jacoby, Benjamin (s. Anm. 67), 47f. 
kaum eine Besonderheit jüdischer Geschichtserzählung. Sie begegnet auch schon in Ademars Schilderung der Ereignisse von 1009 und des Angriffs zehntausender bewaffneter Sarazenen auf das Katharinenkloster am Berg Sinai. Wenn es da heißt, bei ihrem Eintreffen hätten die Feinde schon von weitem den Berg in Feuer und Rauch gehüllt gesehen, wobei alles darauf Liegende samt den Menschen unversehrt geblieben sei, wird auf dramatische Weise der biblisch-heilsgeschichtliche Moment des brennenden Dornbuschs reaktualisiert. Das Wunder der neuerlich vom Sinai herabkommenden Wahrheit leitete dann auch den Sinneswandel des Kalifen bis hin zum Wiederaufbau der zerstörten Grabeskirche in Jerusalem ein und erklärte ihn. ${ }^{69}$

69 Ademar, III.47, 167. 